Matthew P. Johnson · Lyn R. Griffiths

\title{
A genetic analysis of serotonergic biosynthetic and metabolic enzymes in migraine using a DNA pooling approach
}

Received: 29 June 2005 / Accepted: 12 August 2005 / Published online: 1 October 2005

(C) The Japan Society of Human Genetics and Springer-Verlag 2005

\begin{abstract}
Migraine is a common debilitating primary headache disorder with significant mental, physical and social health implications. The brain neurotransmitter 5hydroxytryptamine (5-HT; serotonin) is involved in nociceptive pathways and has been implicated in the pathophysiology of migraine. With few genetic studies investigating biosynthetic and metabolic enzymes governing the rate of 5-HT activity and their relationship to migraine, it was the objective of this study to assess genetic variants within the human tryptophan hydroxylase (TPH), amino acid decarboxylase (AADC) and monoamine oxidase A (MAOA) genes in migraine susceptibility. This objective was undertaken using a highthroughput DNA pooling experimental design, which proved to be a very accurate, sensitive and specific method of estimating allele frequencies for single nucleotide polymorphism, insertion deletion and variable number tandem repeat loci. Application of DNA pooling to a wide array of genetic loci provides greater scope in the assessment of population-based genetic association study designs. Despite the application of this high-throughput genotyping method, negative results from the two-stage DNA pooling design used to screen loci within the TPH, AADC and MAOA genes did not support their role in migraine susceptibility.
\end{abstract}

Keywords Migraine $\cdot$ Serotonin $\cdot$ DNA pooling $\cdot$ Genetic association

M. P. Johnson · L. R. Griffiths ( $\square)$

Genomics Research Centre, School of Medical Science, Griffith University, PMB 50 GCMC, 9726 Gold Coast, QLD, Australia

E-mail: 1.griffiths@griffith.edu.au

Tel.: + 61-7-55528664

Fax: +61-7-55529081

\section{Introduction}

To reduce the level of genotyping and to vastly reduce the time, labour and expenses required, the analysis of pooled samples of DNA as opposed to individual samples of DNA may provide a more feasible approach to systematically scanning the human genome for associations to multifactorial disorders (Norton et al 2004; Sham et al 2002). The application of DNA pooling involves a twofold approach where an estimate of allele frequencies at a particular locus can be obtained and those frequency estimates can then be utilised as a first pass screen of genetic variants assayed for a genetic association study. Individual DNA samples are collectively pooled to incorporate a single sample for subsequent analysis, thus minimising the time, labour and expense associated with individual genotyping.

A wealth of scientific support has implicated the brain neurotransmitter 5-hydroxytryptamine (5-HT; serotonin) as being involved in the pathophysiology of migraine, supporting a proposed serotonergic theory of migraine. Documented evidence of increased 5-HT activity associated with a corresponding decrease in nociception and decreased 5-HT activity levels with a subsequent increase in nociception is indicative of the role of serotonin in pain modulation (Anthony 1987). Fluctuations in 5-HT homeostasis have been documented in migrainous episodes with similar conclusions. Changes in 5-HT serum levels during patient migraine attacks (Ferrari et al 1989) and disruptions within the synthesis (Chugani et al 1999) and metabolism (Ferrari and Saxena 1993) of 5-HT all substantiate the pathophysiological role of 5-HT in migraine pathogenesis.

There has been a comprehensive effort to investigate the physiological, pathophysiological and/or genetic actions of 5-HT interactions with tissue specific 5-HT receptor classes (Johnson et al 2003; Nyholt et al 1996), in addition to studies of the serotonin transporter (5HTT) (Lea et al 2000). However, there have been limited studies relating to the biosynthetic and metabolic 
enzymes governing the rate of 5-HT and their relationship to migraine. It was the aim of this study to therefore investigate genetic variations within the tryptophan hydroxylase (TPH), amino acid decarboxylase (AADC) and monoamine oxidase A (MAOA) genes and their potential role in migraine susceptibility using a twostage DNA pooling study design.

\section{Materials and methods}

Subjects and diagnosis

Phenotypic data for the diagnosis of typical migraine $(\mathrm{MO}+\mathrm{MA})$, migraine without aura (MO) and migraine with aura (MA) adhered to specified criteria set by the Headache Classification Committee of the International Headache Society (1988). Using a migraine population-based association cohort consisting of 275 migraineurs and 275 sex-, age ( \pm 5 years)- and ethnicity (Caucasian origin)-matched non-migraineurs, DNA pools were prepared and constructed in triplicate (Sham et al 2002). Each independent migraine DNA pool consisted of 179 individual DNA samples and each independent non-migraine DNA pool consisted of 186 individual DNA samples. Individual DNA samples used for pooling purposes were at an equimolar concentration of $8 \mathrm{ng} \mu \mathrm{l}^{-1}$.

DNA pool genotyping

The TPH $-7065 \mathrm{C} \rightarrow \mathrm{T}$ promoter SNP was amplified using PCR technology and primers previously published (Paoloni-Giacobino et al 2000). Allelic discrimination of the TPH SNP in the DNA pool constructs using the sense extension primer was performed using the SNaPshot single base extension assay on a 3100 Genetic Analyzer (Applied Biosystems, Foster City, CA, USA). The AADC $4 \mathrm{bp}$ insertion deletion (indel) polymorphism was amplified using PCR technology and primers previously published (Speight et al 2000). Resolution of the AADC indel was performed using capillary-based electrophoresis on a 310 Genetic Analyzer (Applied Biosystems). Residing $\sim 1.2 \mathrm{~kb}$ upstream from the ATG translation initiation codon, the MAOA promoter

Table 1 DNA pool $\chi^{2}$ analysis of the TPH $-7065 \mathrm{C} \rightarrow \mathrm{T}$ promoter SNP ${ }^{a, b}$

\begin{tabular}{llll}
\hline Allele frequency (count) estimates & & \\
\hline DNA Pool & $\mathrm{C}$ & $\mathrm{T}$ & Total \\
\hline Migraine $(n=179)$ & $222(0.62)$ & $136(0.38)$ & 358 \\
Non-migraine $(n=186)$ & $201(0.54)$ & $171(0.46)$ & 372 \\
Total & 423 & 307 & 730 \\
\hline
\end{tabular}

a Allele frequency estimates denoted in parentheses

b $\chi^{2}=4.77, P=0.029$
VNTR was amplified using PCR technology and primers previously published (Speight et al 2000). Resolution of the MAOA promoter VNTR was performed using capillary-based electrophoresis on a 310 Genetic Analyzer.

Individual genotyping

Application of a real-time PCR SNP genotyping assay was employed to evaluate the individual genotype and allele frequencies for the TPH SNP. A full description of this individual genotyping method that incorporates a novel set of mathematical criteria for determining ambiguous genotypes has been previously described (Johnson et al 2004).

\section{DNA pool statistical analysis}

TPH SNP and AADC insertion deletion loci: To alleviate unbiased estimates of pooled allele frequencies, the magnitude of allele-specific fluorescent signals were subjected to a correction factor $(k)$ obtained from previously known individual sample allele specific amplifications (Hoogendoorn et al 2000). Depending upon the magnitude of experimental error produced in the estimation of pooled allele frequencies, a classical $\chi^{2}$-test statistic or an adjusted $\chi^{2}$-test statistic $\left(\chi_{\text {adj }}^{2}\right)$ was used to assess the null hypothesis (Le Hellard et al 2002; Visscher and Le Hellard 2003).

MAOA VNTR locus: Estimated allele frequencies were determined by allele-specific peak heights expressed as a percentage of the sum of the allele peak heights and statistically assessed by the CLUMP T1 $\chi^{2}$ statistic (Sham and Curtis 1995).

\section{Individual genotype statistical analysis}

Statistical assessment of individual genotype and allele counts were performed by standard contingency table $\chi^{2}$ analyses.

\section{Results}

Estimates of the between migraine and between nonmigraine pool variations were negligible, warranting standard $\chi^{2}$ contingency table analysis of both the TPH SNP and AADC indel loci. The pooled allele frequency analysis between migraine and non-migraine pools for the TPH SNP exceeded the nominal "relaxed" pooled statistical threshold $(\alpha=0.1)$ (Table 1). Using a twostage DNA pool experimental design, this nominal pooled result was then subjected to individual genotyping. Observed individual genotype and allele frequency data of the migraine population-based association cohort used to verify the TPH pooled SNP result (see 
Table 2 Observed individual genotype and allele frequency counts for the TPH-7065C $\rightarrow$ T promoter SNP ${ }^{a, b}$

\begin{tabular}{|c|c|c|c|c|c|}
\hline \multirow[t]{2}{*}{ Migraine cohort } & \multicolumn{3}{|l|}{ Genotype } & \multicolumn{2}{|l|}{ Allele } \\
\hline & $\mathrm{CC}$ & $\mathrm{CT}$ & TT & $\mathrm{C}$ & $\mathrm{T}$ \\
\hline Migraine combined $(n=275)$ & $98(0.39)$ & $108(0.44)$ & $41(0.17)$ & $304(0.62)$ & $190(0.38)$ \\
\hline $\mathrm{MO}^{\mathrm{c}}(n=121)$ & $38(0.39)$ & $38(0.39)$ & $20(0.18)$ & $114(0.59)$ & $78(0.41)$ \\
\hline $\mathrm{MA}^{\mathrm{d}}(n=78)$ & $60(0.40)$ & $70(0.46)$ & $21(0.14)$ & $190(0.63)$ & $112(0.37)$ \\
\hline Non-migraine $(n=275)$ & $89(0.38)$ & $100(0.43)$ & $45(0.19)$ & $278(0.59)$ & $190(0.41)$ \\
\hline
\end{tabular}

${ }^{a}$ Allele frequencies denoted in parentheses

${ }^{\mathrm{b}}$ No significant differences were observed between either of the migraine phenotypes and the non-migraine group $(P>0.05)$

${ }^{\mathrm{c}}$ Migraine without aura

${ }^{\mathrm{d}}$ Migraine with aura

Table 1) are presented in Table 2. Using the more standard statistical threshold $(\alpha=0.05)$ to assess individual genotypes of the TPH locus, both genotypic and allelic association analyses were nonsignificant (Table 2).

Stratification of the migraine phenotype in order to independently assess the MO- and MA-only phenotypes for the TPH SNP did not present significant genotypic or allelic associations upon analyses either (Table 2). Pooled allele frequency analysis between the migraine and non-migraine pooled replicates for the AADC indel and MAOA VNTR loci did not satisfy the nominal "relaxed" pooled statistical threshold. These data therefore did not warrant individual genotyping analysis.

\section{Discussion}

With the exception of Marziniak et al (2004) there has been a dearth of migraine population genetic research investigating the potential role of 5-HT biosynthetic and metabolic enzymes. For the tested TPH SNP, pooled allele frequency analysis was positively identified to satisfy the nominal "relaxed" statistical threshold commonly used in DNA pooling applications $(\alpha=0.1)$ (Norton et al 2004; Sham et al 2002). However, individual genotyping results did not validate the initial pooling analysis. Although the tested TPH promoter SNP had functional relevance for genetic analysis of 5HT related disorders, there was no evidence from this research for involvement of this marker in typical migraine (MO + MA), MO or MA susceptibility. Displaying a high degree of accuracy in the estimation of the TPH SNP pooled allele frequencies, a maximum discrepancy of $5 \%$ from individual allele frequencies when compared to pooled allele frequency estimates was observed. With particular reference to independent population genetic investigation of the same TPH SNP, Paoloni-Giacobino et al (2000) reported frequencies for the $\mathrm{C}$ and $\mathrm{T}$ alleles of 0.59 and 0.41 , respectively. Based on individual genotypings, these data are within $5 \%$ of the current pooled allele frequency estimates and are identical to the current individual allele frequency observations.
Pooled analysis of the AADC indel failed to satisfy the "relaxed" statistical threshold $(\alpha=0.1)$. Individual genotyping was therefore not warranted, indicating that there was no evidence that the AADC indel was involved in typical migraine (MO + MA) susceptibility. However, the use of DNA pooling on a novel (indel) genetic locus again demonstrated a high degree of accuracy in the estimation of allele frequencies (to within 5\%). For a population data sample size of 158 chromosomes, the AADC indel is documented in the NCBI SNP database (dbSNP) with observed allele frequencies of the insertion and deletion $4 \mathrm{bp}$ variant of 0.722 and 0.278 , respectively (refSNP ID: rs3837091). These observed frequencies of individual genotyping results compare well with the current DNA pooling estimation of the control groups insertion (0.77) and deletion (0.23) allelic frequencies.

Resolution of the $30 \mathrm{bp}$ MAOA VNTR can be achieved using a slab-gel based approach, although the use of fluorescently labelled sense primers and capillary electrophoresis provides a more quantifiable assessment of each allele (peak height). Based on this relative allele frequency estimate, pooled analysis could not support the involvement of the MAOA VNTR in migraine susceptibility $(P>0.1)$. Individual genotyping was not conducted as this pooled result concurs with the combined male and female allelic association analysis of the same VNTR locus in a German cohort (Marziniak et al 2004). Comparison of pooled VNTR allele frequencies to independent genetic investigations of the same tested variant were greater than 5\% (Deckert et al 1999; Sabol et al 1998; Serretti et al 2002). DNA pool assessment of the MAOA VNTR did not correct for stutter, as VNTR loci do not exhibit this characteristic. There was no correction for differential amplification either. Uncorrected for differential amplification in both the migraine and non-migraine pools, the characteristic preferential amplification often witnessed in shorter alleles over longer alleles may account for the discrepancies in the frequency estimates of the shorter MAOA VNTR alleles.

It was demonstrated that the use of DNA pools did provide an accurate and sensitive measure of allele frequencies for various types of genetic loci. It has been well documented that the use of DNA pooling is a 
successful high-throughput assay for screening SNP loci, this study inclusive. The successful application of DNA pooling to a novel insertion deletion locus and a novel VNTR locus now provides further evidence for the scope of DNA pooling applications to be increased to investigate of genetic variations within the human genome.

Acknowledgements M.P.J. wishes to thank Drs Nigel Williams and Nadine Norton and members of the Owen laboratory from the University of Wales College of Medicine (UWCM) for technical assistance during the DNA pooling experimental design. Work performed at UWCM was supported by a Boehringer Ingelheim Fonds Overseas Travel Award and a Griffith University Long Stay Overseas Scholarship.

\section{References}

Anthony M (1987) Amine metabolism in migraine. In: Blau JN (ed) Migraine. Clinical, therapeutic, conceptual and research aspects. Chapman and Hall, London, pp 303-330

Chugani DC, Niimura K, Chaturvedi S, Muzik O, Fakhouri M, Lee ML, Chugani HT (1999) Increased brain serotonin synthesis in migraine. Neurology 53:1473-1479

Deckert J, Catalano M, Syagailo YV, Bosi M, Okladnova O, Di Bella D, Nothen MM, Maffei P, Franke P, Fritze J, Maier W, Propping P, Beckmann H, Bellodi L, Lesch KP (1999) Excess of high activity monoamine oxidase $\mathrm{A}$ gene promoter alleles in female patients with panic disorder. Hum Mol Genet 8:621-624

Ferrari MD, Odink J, Tapparelli C, Van Kempen GM, Pennings EJ, Bruyn GW (1989) Serotonin metabolism in migraine. Neurology 39:1239-1242

Ferrari MD, Saxena PR (1993) On serotonin and migraine: a clinical and pharmacological review. Cephalalgia 13:151-165

Headache Classification Committee of the International Headache Society (1988) Classification and diagnostic criteria for headache disorders, cranial neuralgias and facial pain. Cephalalgia 8(Suppl 7):1-96

Hoogendoorn B, Norton N, Kirov G, Williams N, Hamshere ML, Spurlock G, Austin J, Stephens MK, Buckland PR, Owen MJ, O'Donovan MC (2000) Cheap, accurate and rapid allele frequency estimation of single nucleotide polymorphisms by primer extension and DHPLC in DNA pools. Hum Genet 107:488-493

Johnson MP, Haupt LM, Griffiths LR (2004) Locked nucleic acid (LNA) single nucleotide polymorphism (SNP) genotype analysis and validation using real-time PCR. Nucleic Acids Res $32: \mathrm{e} 55$
Johnson MP, Lea RA, Curtain RP, MacMillan JC, Griffiths LR (2003) An investigation of the 5-HT2C receptor gene as a migraine candidate gene. Am J Med Genet 117B:86-89

Le Hellard S, Ballereau SJ, Visscher PM, Torrance HS, Pinson J, Morris SW, Thomson ML, Semple CA, Muir WJ, Blackwood DH, Porteous DJ, Evans KL (2002) SNP genotyping on pooled DNAs: comparison of genotyping technologies and a semiautomated method for data storage and analysis. Nucleic Acids Res 30:e74

Lea RA, Dohy A, Jordan K, Quinlan S, Brimage PJ, Griffiths LR (2000) Evidence for allelic association of the dopamine betahydroxylase gene $(\mathrm{DBH})$ with susceptibility to typical migraine. Neurogenetics 3:35-40

Marziniak M, Mossner R, Benninghoff J, Syagailo YV, Lesch KP, Sommer C (2004) Association analysis of the functional monoamine oxidase A gene promotor polymorphism in migraine. J Neural Transm 111:603-609

Norton N, Williams NM, O'Donovan MC, Owen MJ (2004) DNA pooling as a tool for large-scale association studies in complex traits. Ann Med 36:146-152

Nyholt DR, Curtain RP, Gaffney PT, Brimage P, Goadsby PJ, Griffiths LR (1996) Migraine association and linkage analyses of the human 5-hydroxytryptamine (5HT2A) receptor gene. Cephalalgia 16:463-467

Paoloni-Giacobino A, Mouthon D, Lambercy C, Vessaz M, Coutant-Zimmerli S, Rudolph W, Malafosse A, Buresi C (2000) Identification and analysis of new sequence variants in the human tryptophan hydroxylase $(\mathrm{TpH})$ gene. Mol Psychiatry 5:4955

Sabol SZ, Hu S, Hamer D (1998) A functional polymorphism in the monoamine oxidase A gene promoter. Hum Genet 103:273279

Serretti A, Cristina S, Lilli R, Cusin C, Lattuada E, Lorenzi C, Corradi B, Grieco G, Costa A, Santorelli F, Barale F, Nappi G, Smeraldi E (2002) Family-based association study of 5HTTLPR, TPH, MAO-A, and DRD4 polymorphisms in mood disorders. Am J Med Genet 114:361-369

Sham P, Bader JS, Craig I, O'Donovan M, Owen M (2002) DNA Pooling: a tool for large-scale association studies. Nat Rev Genet 3:862-871

Sham PC, Curtis D (1995) Monte Carlo tests for associations between disease and alleles at highly polymorphic loci. Ann Hum Genet 59(Pt 1):97-105

Speight G, Turic D, Austin J, Hoogendoorn B, Cardno AG, Jones L, Murphy KC, Sanders R, McCarthy G, Jones I, McCandless F, McGuffin P, Craddock N, Owen MJ, Buckland P, O'Donovan MC (2000) Comparative sequencing and association studies of aromatic L-amino acid decarboxylase in schizophrenia and bipolar disorder. Mol Psychiatry 5:327-331

Visscher PM, Le Hellard S (2003) Simple method to analyze SNPbased association studies using DNA pools. Genet Epidemiol 24:291-296 